\section{OPEN ACCESS}

Edited by:

Lenin Pavón,

National Institute of Psychiatry Ramon de la Fuente Muñiz (INPRFM), Mexico

Reviewed by:

Luciano David D'Attilio, CONICET Rosario, Argentina

Jens Staal,

Ghent University, Belgium

*Correspondence:

Carolina Francelin francelin.carolina@gmail.com

Wilson Savino

wilson.savino@fiozcruz.br;

savino.w@gmail.com

tThese authors have contributed equally to this work and share first authorship

¥These authors share senior authorship

Specialty section:

This article was submitted to Signaling,

a section of the journal Frontiers in Cell and Developmental Biology

Received: 15 February 2021 Accepted: 25 March 2021

Published: 13 April 2021

Citation:

Francelin $C$, Veneziani $L P$

Farias AdS, Mendes-da-Cruz DA and Savino W (2021) Neurotransmitters Modulate Intrathymic T-cell

Development.

Front. Cell Dev. Biol. 9:668067. doi: 10.3389/fcell.2021.668067

\title{
Neurotransmitters Modulate Intrathymic T-cell Development
}

\section{Carolina Francelin ${ }^{1,2,3 * t}$, Luciana Peixoto Veneziani ${ }^{2,4,5 t}$, Alessandro dos Santos Farias ${ }^{1,2}$, Daniella Arêas Mendes-da-Cruz 2,4,5,6* and Wilson Savino ${ }^{2,4,5 * \neq}$}

${ }^{1}$ Autoimmune Research Laboratory, Department of Genetics, Microbiology and Immunology, Institute of Biology, University of Campinas, Campinas, Brazil, ${ }^{2}$ National Institute of Science and Technology on Neuroimmunomodulation (INCT-NIM), Oswaldo Cruz Institute, Oswaldo Cruz Foundation, Rio de Janeiro, Brazil, ${ }^{3}$ Department of Ophthalmology and Visual Sciences, School of Medicine, University of Alabama at Birmingham, Birmingham, AL, United States, ${ }^{4}$ Laboratory on Thymus Research, Oswaldo Cruz Foundation, Oswaldo Cruz Institute, Rio de Janeiro, Brazil, ${ }^{5}$ Rio de Janeiro Research Network on Neuroinflammation (RENEURIN), Rio de Janeiro, Brazil, ${ }^{6}$ School of Pharmacy and Biomedical Sciences, University of Central Lancashire, Preston, United Kingdom

The existence of a crosstalk between the nervous and immune systems is well established. Neurotransmitters can be produced by immune cells, whereas cytokines can be secreted by cells of nervous tissues. Additionally, cells of both systems express the corresponding receptors. Herein, we discuss the thymus as a paradigm for studies on the neuroimmune network. The thymus is a primary lymphoid organ responsible for the maturation of $\mathrm{T}$ lymphocytes. Intrathymic T-cell development is mostly controlled by the thymic microenvironment, formed by thymic epithelial cells (TEC), dendritic cells, macrophages, and fibroblasts. Developing thymocytes and microenvironmental cells can be influenced by exogenous and endogenous stimuli; neurotransmitters are among the endogenous molecules. Norepinephrine is secreted at nerve endings in the thymus, but are also produced by thymic cells, being involved in controlling thymocyte death. Thymocytes and TEC express acetylcholine receptors, but the cognate neurotransmitter seems to be produced and released by lymphoid and microenvironmental cells, not by nerve endings. Evidence indicates that, among others, TECs also produce serotonin and dopamine, as well as somatostatin, substance P, vasoactive intestinal peptide (VIP) and the typical pituitary neurohormones, oxytocin and arg-vasopressin. Although functional data of these molecules in the thymus are scarce, they are likely involved in intrathymic $T$ cell development, as exemplified by somatostatin, which inhibits thymocyte proliferation, differentiation, migration and cytokine production. Overall, intrathymic neuroimmune interactions include various neurotransmitters, most of them of non-neuronal origin, and that should be placed as further physiological players in the general process of T-cell development.

Keywords: neurotransmitters, thymus, thymic epithelial cells, T-cell development, thymocytes

\section{INTRODUCTION}

The concept of neuroimmune crosstalk was established several decades ago. One key factor in determining such communication is the fact that both the nervous and immune systems use similar molecular moieties, and therefore apply a common syntax to communicate with each other. Accordingly, classic types of neurotransmitters can be produced by immune cells, whereas 
cytokines can be secreted by cells of nervous tissues. In the same vein, cells from the two systems express the correlated receptors, although signal transduction may be specific for a given cell type. Herein, we discuss the thymus as a paradigm for the expression and role of different kinds of neurotransmitters, particularly of non-neuronal origin.

The thymus is a primary lymphoid organ responsible for the generation of $\mathrm{T}$ lymphocytes in vertebrates, from fish to mammals (Geenen and Savino, 2019). This process is dependent on interactions controlled by the thymic tridimensional network, composed of thymic epithelial cells (TEC), thymic dendritic cells (TDC), macrophages, fibroblasts; as well as the extracellular matrix, cytokines, chemokines, hormones; and components of the nervous system. During thymocyte differentiation, bone marrow-derived early T-cell precursors (ETP) enter the organ by the corticomedullary region of the thymic lobules and subsequently migrate to the subcapsular region. From this region, immature thymocytes, including those bearing the phenotypes $\mathrm{TCR}^{-} \mathrm{CD}^{-} \mathrm{CD}^{-} \mathrm{CD}^{-}$(double-negative or $\mathrm{DN}$, standing for the membrane expression of CD4 and $\mathrm{CD} 8$ ) and $\mathrm{TCR}^{\text {low }} \mathrm{CD} 3^{\text {low }} \mathrm{CD} 4^{+} \mathrm{CD}^{+}$(double-positive for the same markers, or DP) migrate to the inner cortex, and then to the cortico-medullary region. Developing cells next migrate to the medullary region, where they become mature $\mathrm{TCR}^{\text {high }} \mathrm{CD}^{\text {high }}{ }^{\mathrm{CD}} 4^{+} \mathrm{CD}^{-}$(single-positive for CD4 or CD4SP) or $\mathrm{TCR}^{\text {high }} \mathrm{CD}^{\text {high }} \mathrm{CD}^{-} \mathrm{CD}^{+}$(single-positive for $\mathrm{CD} 8$ or CD8SP) cells (summarized in Figure 1A). Those cells ultimately migrate to the cortico-medullary region and leave the thymus to specific regions in peripheral lymphoid organs (Francelin and Verinaud, 2011; Savino et al., 2016).

The migration facilitates the encounter and the interactions of thymocytes with different components of the thymic microenvironment. For example, the TCR/CD3 complex, expressed by thymocytes, interacts with self-antigens presented by molecules of the major histocompatibility complex (MHC), expressed by microenvironmental cells, including TEC and TDC. Thymocytes bearing TCR/CD3 complexes that interact with low or medium affinity with MHC-presented self-antigens are positively selected and continue their maturation process. Conversely, thymocytes bearing TCR/CD3 complexes that interact with high affinity with MHC-presented self-antigens are negatively selected and die by apoptosis. Those selective processes prevent the exit of dysfunctional mature $\mathrm{T}$ cells or cells with autoimmune potential (Francelin and Verinaud, 2011; Savino et al., 2016).

As for components of the nervous system that could impact thymus physiology, nerve fibers and neurotransmitters are spread through the parenchyma, and both thymocytes and TECs express neurotransmitter receptors. This can be exemplified by the intrathymic presence of autonomic nervous system (ANS) fibers, providing noradrenergic fibers within the thymus parenchyma (Leposavić et al., 2008; Godinho-Silva et al., 2019). The main source of these nerves is the postganglionic neurons in the upper paravertebral ganglion of the sympathetic chain, predominantly from the upper cervical and stellate ganglia (Nance and Sanders, 2007; Leposavić et al., 2008). Most of the nerves are composed of noradrenergic fibers that enter the thymus through the capsule and are distributed along with the capsule and septa as fibers or following the vasculature of the connective tissue that forms the organ. Neuronal-derived norepinephrine release is modulated by presynaptic receptors of noradrenergic axonal terminals, which express the $\alpha 2$ adrenergic presynaptic receptors, muscarinic and nicotinic acetylcholine receptors, as well as purinergic receptors and receptors for prostaglandins (PGE2) (Haskó et al., 1995), thus illustrating a complex intrathymic control of norepinephrine release at the nerve endings.

Peptidergic innervation can also be seen within the organ, and comprise, for example, Neuropeptide Y, neurotensin, vasoactive intestinal peptide (VIP) among others (Mignini et al., 2011, 2014). Nevertheless, it is important to point out that neurotransmitters of non-neuronal origin can also be found in the thymus, and that parenchymal lymphoid and non-lymphoid cells can express the respective cognate receptors, as seen below.

\section{INTRATHYMIC EXPRESSION OF NON-NEURONAL NEUROTRANSMITTERS AND THEIR CORRESPONDING RECEPTORS}

As mentioned above, neurotransmitters are constitutively produced in the thymus by both autonomic innervation as well as thymic cells (Leposavić et al., 2008; Mignini et al., 2014). They comprise amino acids, monoamines, and peptides, which, as a whole, participate in the general process of $\mathrm{T}$ cell differentiation. Accordingly, both thymic microenvironmental cells and thymocytes express specific receptors (see Table $\mathbf{1}$ ).

For example, there is an intrathymic cholinergic system represented by acetylcholine (ACh), which is synthesized and released by TECs as well as thymocytes (Rinner et al., 1999; Kawashima and Fujii, 2004; Panneck et al., 2014). These same cell types also express the corresponding cholinergic receptors, thus pointing to a non-neuronal autocrine/paracrine cholinergic circuit acting within the organ (Kawashima and Fujii, 2004). In fact, intrathymic ACh impacts thymocyte development directly by acting upon thymocyte via cholinergic receptors; or indirectly, through microenvironmental cells, with consequences on developing thymocytes (Rinner et al., 1999; Kawashima and Fujii, 2004). Actually, when thymocytes were co-cultured with TECs in the presence of ACh, a pro-apoptotic effect was observed. This effect was reversed after the treatment with a nicotinic receptor antagonist, indicating that thymic cells are responsive to cholinergic modulation (Rinner et al., 1999). Additionally, multiple nicotinic receptor subunits have been described as being expressed by thymocytes and TECs, including $\alpha 2, \alpha 3, \alpha 5, \alpha 7, \beta 4$, $\varepsilon$ in TECs and $\alpha 3, \alpha 5, \alpha 7, \beta 2, \beta 4$ in thymocytes (Mihovilovic et al., 1997; Kawashima and Fujii, 2004). The fact that both cell types express nicotinic receptor subunits reinforces the idea that ACh may be an important player in TEC-thymocyte interactions (Rinner et al., 1999; Kawashima and Fujii, 2004). The subunit expression also varies according to the cell maturation profile, as it has been shown that especially $\alpha 3$ and $\beta 4$ are decreased in more mature single-positive thymocytes, indicating that ACh may also 

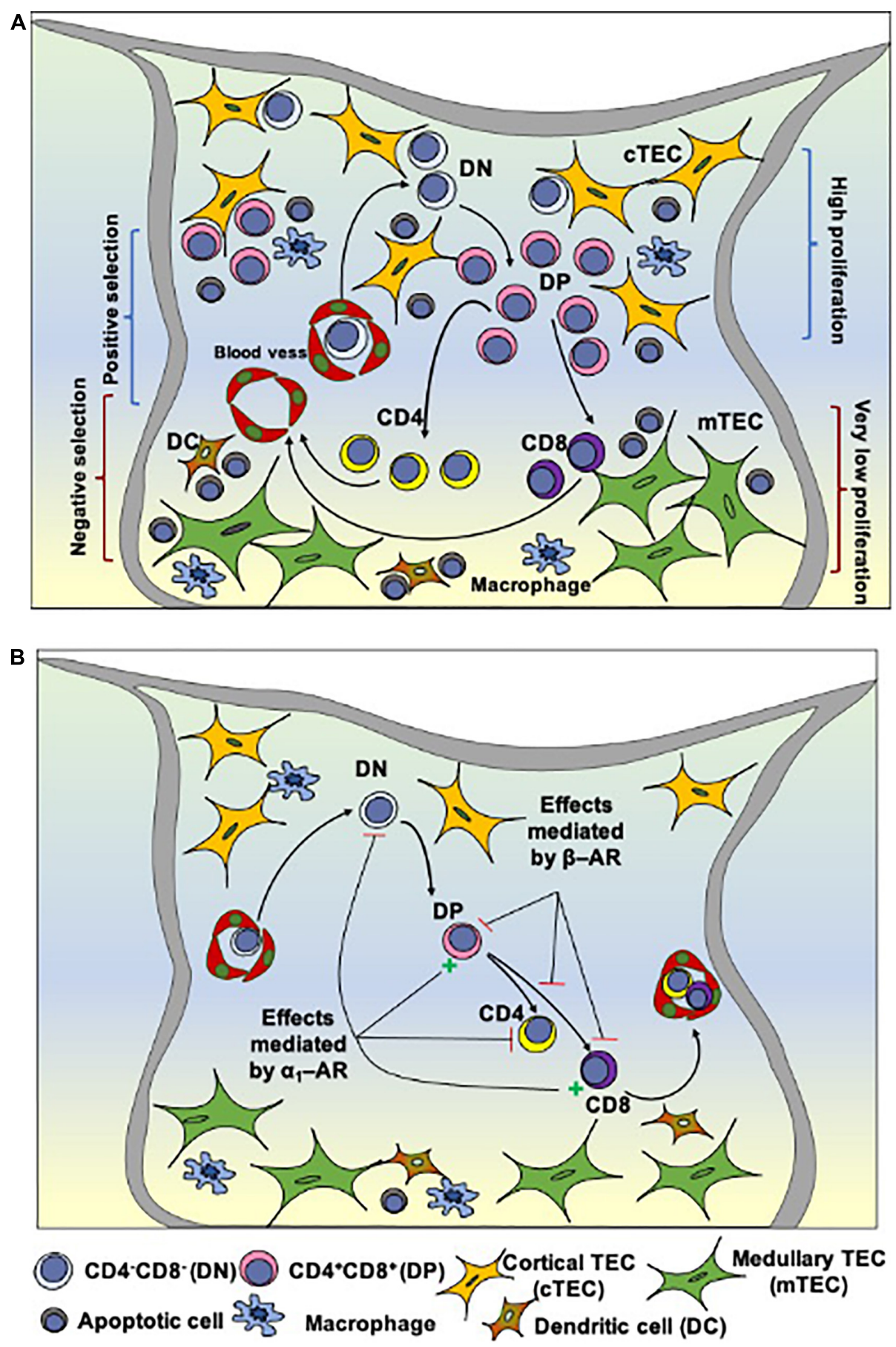

FIGURE 1 | Intrathymic T cell differentiation within the thymic microenvironment and stages that can be modulated by norepinephrine. (A) Shows schematically the general process of thymocyte differentiation, in the context of the thymic microenvironment. Bone marrow-derived precursors enter the organ through capillaries at the corticomedullary junction and migrate toward the outer cortex where they proliferate, but do not express the CD3/TCR complexes as well as the accessory molecules CD4 and CD8. There CD4/CD8 double-negative cells (DN) evolve to express TCR as well as CD4 and CD8 (becoming double-positive cells, DP) and, under the control of the thymic microenvironment, undergo positive selection, with positively-selected thymocytes migrating toward the medulla, where some of them will die by negative selection. Mature CD4 or CD8 single-positive thymocytes will eventually leave the thymus. (B) Depicts the influence of $\alpha$ and $\beta$-adrenergic receptors (AR) along with thymocyte differentiation in the rat thymus. Activation of $\alpha 1$-AR reduces the frequency of DN cells and increases DP cells. It is hypothesized that signaling through $\beta$-AR (via regulation of Thy-1 expression) modulates the selection process, reducing positive and/or increasing negative selection, and detains thymocyte differentiation, while $\alpha 1-A R$ signaling may prevent the differentiation of positively selected cells toward the CD4+SP phenotype. Stellate yellow cells: cortical TECs; stellate green cells: medullary TECs; round cells with a purple nucleus: thymocytes in different stages of development; blue cells: macrophages; brown cells: dendritic cells (DCs). Reduction $=-$ and increase $=+$ Adapted from Leposavić et al. (2008) and Savino et al. (2015). 
TABLE 1 | Intrathymic expression of non-neuronal neurotransmitters and their corresponding receptors.

\begin{tabular}{|c|c|c|c|c|c|}
\hline \multirow[t]{2}{*}{$\begin{array}{l}\text { Non-neuronal } \\
\text { neurotransmitter }\end{array}$} & \multicolumn{2}{|c|}{ Cell type producer } & \multicolumn{2}{|c|}{$\begin{array}{l}\text { Cell types expressing the } \\
\text { corresponding receptors }\end{array}$} & \multirow[t]{2}{*}{ References } \\
\hline & TEC & Thymocytes & TEC & Thymocytes & \\
\hline Acetylcholine & + & + & $\begin{array}{l}\alpha 2, \alpha 3, \alpha 5 \\
\alpha 7, \beta 4, \varepsilon^{\star}\end{array}$ & $\alpha 3, \alpha 5, \alpha 7, \beta 2, \beta 4^{*}$ & $\begin{array}{l}\text { Rinner et al., 1999; Kawashima and Fujii, 2004; } \\
\text { Panneck et al., } 2014\end{array}$ \\
\hline Dopamine & + & $\begin{array}{l}\text { Lowlevels } \\
\text { detected }\end{array}$ & ND & D1, D2, D3, D4, D5 & $\begin{array}{l}\text { Pilipović et al., 2008; Mignini et al., 2009, 2013; } \\
\text { Lifantseva et al., } 2016\end{array}$ \\
\hline Norepinephrine & + & + & $\alpha 1, \beta 1, \beta 2^{\star \star}$ & $\alpha 1, \beta 2^{\star \star}$ & $\begin{array}{l}\text { Marchetti et al., 1994; Leposavić et al., 2008; } \\
\text { Pešić et al., 2009; Roggero et al., } 2011\end{array}$ \\
\hline Serotonin & ND & + & ND & $\begin{array}{l}\text { 5-HT1B, 5-HT1F, 5-HT2A, } \\
\text { 5-HT2B, 5-HT6, 5-HT7 }\end{array}$ & Stefulj et al., 2000; Lifantseva et al., 2017 \\
\hline $\begin{array}{l}\text { Vasoactive } \\
\text { intestinal peptide }\end{array}$ & + & ND & ND & VIPR, VIP ${ }_{1} R$ & Delgado et al., 1996a,b; Silva et al., 2006 \\
\hline Neuropeptide $Y$ & + & ND & ND & $Y_{1}, Y_{2}, Y_{3}$ (possibly) & Medina et al., 2000; Silva et al., 2006 \\
\hline $\begin{array}{l}\text { Calcitonin gene } \\
\text { related peptide }\end{array}$ & + & ND & ND & $\mathrm{CGPR}_{1}$ & Kurz et al., 1995; Silva et al., 2006 \\
\hline Substance P & + & + & ND & NK-1R & Santoni et al., 2002; Silva et al., 2006 \\
\hline Oxytocin & + & ND & ND & OTR & $\begin{array}{l}\text { Robert et al., 1991; Hansenne et al., 2005; } \\
\text { Savino et al., } 2016\end{array}$ \\
\hline Arg-Vasopressin & + & ND & ND & $\mathrm{V} 1 \mathrm{bR}$ & $\begin{array}{l}\text { Robert et al., 1991; Hansenne et al., 2005; } \\
\text { Savino et al., } 2016\end{array}$ \\
\hline Somatostatin & + & ND & sst1, sst2A & sst2A, sst3, sst4 & Ferone et al., 2002; Silva et al., 2006 \\
\hline
\end{tabular}

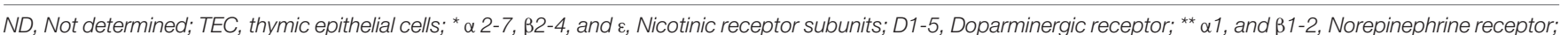

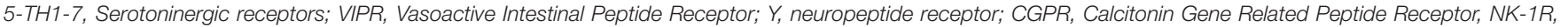
Neurokinin 1-Receptor, OTR, Oxytocin Receptor, V1bR, Vasopressin V1b Receptor, sst 2-4, Somatostatin Receptor.

play a role in intrathymic T-cell differentiation (Mihovilovic et al., 1997). Moreover, an autocrine loop may take place in endothelial cells, since Ach is produced by these cells, which also express cholinergic receptors (Kawashima and Fujii, 2004). A further non-excludent hypothesis is that Ach produced by endothelial cells in the thymus act through a paracrine way, to modulate the interactions between thymocytes and endothelial cells and also TEC-thymocyte interaction.

In a second vein, the stimulation of the Ach receptor modulates nitric oxide which in turn acts by inducing vasodilation controlling permeability and blood circulation (Kawashima and Fujii, 2004).

Regarding monoamines neurotransmitters, the catecholamine system seems to be a major player in terms of the roles of neurotransmitters in thymocyte development. Norepinephrine (NE) is the main catecholamine of the ANS within the thymus. Interestingly, in addition to the neuronal input, the thymus presents a non-neuronal catecholaminergic network; thymocytes and TECs express catecholaminergic receptors and enzymes necessary for NE production, such as tyrosine hydroxylase (Leposavić et al., 2008). In this respect, inhibition of this enzyme evoked reduction in NE contents in rat thymocytes and adult thymus (Radojevíc et al., 2014).

Catecholamines secreted and released intrathymically engage with $\alpha$ and $\beta$ adrenergic receptors expressed by thymocytes and TECs, shown in Table $\mathbf{1}$ and Figure $\mathbf{1 B}$ (Leposavić et al., 2008; Roggero et al., 2011). Briefly, thymocytes of adult mice and fetuses express $\beta$-AR binding sites (Singh et al., 1979). Interestingly, in the rat thymus, $\beta 2-A R$, which is the most expressed adrenergic receptor in the organ, can be modulated by sexual hormones, as it was demonstrated that $\beta 2-\mathrm{AR}$ density can vary according to the marked alterations of the sex steroid hormone milieu in female rats (Marchetti et al., 1994). In a second vein, immature thymocytes in the mouse thymus express lower amounts of $\beta$-AR than their mature counterparts (Radojcic et al., 1991), suggesting that the adrenergic system participates in early $\mathrm{T}$ cell development through the $\alpha$-AR induced signaling pathway (Kavelaars, 2002; Pešić et al., 2009). The $\alpha$-AR receptors detected in the rat and human thymuses are not observed in peripheral blood mononuclear cells, suggesting that the expression of these receptors is strictly regulated during the T-cell development (Kavelaars, 2002). It is also interesting to note that non-lymphoid cells represent the major populations expressing $\alpha 1-\mathrm{AR}$, even though distinct thymocyte populations could also express this receptor, mainly in immature thymocytes (Pešić et al., 2009).

Of note, phenylethanolamine N-methyltransferase (PNMT), the enzyme that converts norepinephrine to epinephrine, was also detected in the cortex and medulla of the rodent thymus, with higher density in the cortex (Warthan et al., 2002). Although the specific cell type expressing this enzyme was not detected, thymocytes would be an appropriate candidate due to tyrosine hydroxylase expression in these cells (Warthan et al., 2002; Leposavić et al., 2008). The presence of this enzyme in the thymus suggests de novo synthesis of epinephrine in the thymus, and that thymocytes could uptake NE and convert to epinephrine (Warthan et al., 2002; Leposavić et al., 2008). Taking into account that the affinity of epinephrine for $\beta 2-\mathrm{AR}$ is much higher than $\mathrm{NE}$ and that $\beta 2$-AR is the major $\beta$-AR subtype in the thymus 
(Marchetti et al., 1994), it is conceivable to think that such a conversion could enhance $\beta 2$-AR driven effects upon thymocyte differentiation (Leposavić et al., 2008).

Dopamine (DA) levels were also detected in rat thymocytes, although in low levels (Pilipović et al., 2008). On the other hand, DA stores were reported in the rat thymus, located mainly in the corticomedullary and medulla of the thymic lobules, alongside vesicular monoamine transporters and thymic cells that express dopaminergic receptors (Mignini et al., 2009). This indicates that catecholamines, and especially DA, of thymic origin, can modulate the final stages of intrathymic $\mathrm{T}$ cell differentiation (Mignini et al., 2009, 2013; Lifantseva et al., 2016).

Immunoreactivity for the five dopamine receptor subtypes (D1, D2, D3, D4, and D5) were detected in the thymic tissue, with higher expression in cortico-medullary junction and medulla (Mignini et al., 2009, 2013). Since D1 and D3 expression is detected in the rat thymus as early as day 16 of fetal development (E16) and D5 appeared 1 day later, both DA stimulatory (D2, D3, and D4) and inhibitory (D1 and D5) pathways may be involved in the early thymus organogenesis and upon the initial events of thymocyte differentiation and migration (Lifantseva et al., 2016). Accordingly, DA receptors expression pattern is modified as thymocytes differentiate into the CD4SP or CD8SP subpopulations, and between them, suggesting that the intrathymic dopaminergic system plays a role on thymocyte lineage progression within the organ (Mignini et al., 2013).

Encompassing all monoamine neurotransmitters, thymic cells express components of the serotonergic system, as exemplified by the production of serotonin by thymocytes. Moreover, serotonergic receptors are detected in both embryonic and adult rat thymocytes (Table 1; Stefulj et al., 2000; Lifantseva et al., 2017) and their signaling seems to be related to the control of cytokine production (IL-4 and IL-2) by developing thymocytes (Shenoy et al., 2013).

The intrathymic peptidergic neurotransmitter complex, produced by thymocytes and microenvironmental cells (in addition to nerve fibers) comprises neuropeptide Y (NPY), somatostatin (SOM), substance P (SP), calcitonin-gene-relatedpeptide (CGRP), neurotensin, vasoactive intestinal polypeptide (VIP), PACAP (pituitary adenylate cyclase-activating peptide) as well as the oxytocin and Arg-vasopressin, which play a role in the thymus microenvironment as well as lymphocyte maturation (Silva et al., 2006; Mignini et al., 2011). In the human thymus, NPY and VIP are the major peptidergic components modulating $\mathrm{T}$ cell development (Medina et al., 2000; Silva et al., 2006; Mignini et al., 2011). The intracellular signaling mediated by NPY through different functional NPY receptors exerts an inhibitory chemotactic and proliferative effect on the developing thymocytes, suggesting a role for NPY in intrathymic $\mathrm{T}$ cell migration and emigration, which can be modified by the aging process (Medina et al., 2000). The presence of $\mathrm{NPY}^{+}$fibers in the thymus associated with mast cells and macrophages, in addition to thymocytes, suggests a role for NPY in the maintenance of thymic non-lymphoid cell populations, which, in turn, contributes to thymocyte development (Mignini et al., 2011, 2014).
As regards VIP, it has been shown that it induces the differentiation of DP into CD4-SP cells, as ascertained by $T$ cell lines (Pankhaniya et al., 1998). In a second vein, it has been demonstrated that DP and SP, but not DN thymocytes, express VIP and VIP 1 receptor (VIP1-R) genes, indicating a possible autocrine/paracrine role for VIP in thymocyte differentiation, proliferation, and survival (Delgado et al., 1996a,b). Interestingly, in vitro thymocyte proliferation and cytokine production were inhibited after the TCR/CD3 complex stimulation in the presence of VIP (Xin et al., 1994), although in vivo, effects on thymocyte proliferation were not observed following VIP treatment. However, rat thymic cells that received VIP antagonists (VIP-A1) had enhanced mitotic activity (Trejter et al., 2001), indicating that VIP effects are dependent on the thymic microenvironmental components. VIP also seems to inhibit cell death as it has also been demonstrated that both VIP, as well as PACAP27 and PACAP38 peptides, can inhibit spontaneous thymocyte death and dexamethasoneinduced death through a single receptor, VIP-R (Delgado et al., 1996a). Of note is also the fact that NPY, VIP, and PACAP inhibit thymocyte chemotactic response to N-Formyl-methionylleucyl-phenylalanine, a well-known lymphocyte chemoattractant (Schubert and Müller, 1989).

Yet, human thymocytes express different subtypes of somatostatin receptor (SSRs) during the developing process, which are activated upon binding with their ligands, the somatostatin (SOM) produced by TECs. The intracellular pathways mediating the SOM-dependent activities are involved in the maturation and selection of $\mathrm{T}$ cell repertoire through regulating the proliferation and maturation process of immature thymocytes, which include their migration through thymus stroma, cytokine production, and thymic export (Ferone et al., 2002; Silva et al., 2006).

Substance $\mathrm{P}$ is endogenously produced in the thymus from different species by thymocytes and TECs, being mainly involved in the thymocytes rescue from spontaneous and NK-1R antagonist (SR140333)-induced apoptosis (Santoni et al., 2002; Silva et al., 2006).

Calcitonin gene-related peptide (CGRP) and its cognate receptor are also constitutively expressed in the thymus (Kurz et al., 1995). Both ligand and receptor are expressed by cells in the medulla and corticomedullary junction of the thymic lobules, suggesting the involvement of CGRP upon thymocyte proliferation during positive selection (Kurz et al., 1995; Mignini et al., 2014), although definitive functional studies are still needed.

Lastly, oxytocin and vasopressin are present in the human thymus and TECs can constitutively produce both neurohormones (Moll et al., 1988; Robert et al., 1991; Savino et al., 2016). Their function in thymocyte development is still not clear, but they seem to be involved in the control of CD8-SP cells cycle (Robert et al., 1991; Hansenne et al., 2005; Savino et al., 2016), as well as in the expression of tissue-specific antigens by the thymic epithelium, with consequent effect upon thymocyte selection process, particularly negative selection events (Geenen and Savino, 2019).

Overall, neurotransmitters exert a complex role in thymic microenvironment and, as consequence, in thymocyte 
differentiation. Since a diverse number of thymic cells are able to secrete and respond to those molecules, neurotransmitters can act directly on thymocytes or on stromal and endothelial cells. Hence, this data can lead us to the hypothesis that neurotransmitters affect the release of immunocompetent T-cells which will alter peripheral immune responses.

\section{CONCLUSION}

Taken together, the data discussed herein unravel the complex range of interactions in the thymus that are mediated by neurotransmitters and can modulate the thymus physiology by the induction and/or inhibition of cell survival, proliferation, differentiation, and migration. Accordingly, neurotransmitters seem to provide a complex network of interactions, involving microenvironmental cells, endothelial cells and developing thymocytes ultimately modulating the intrathymic T-cell development. Conceptually, these findings lead to the notion that neurotransmitters, of both neuronal and non-neuronal origin, have distinct functions in the thymus, which impact T-cell development. In this respect, it is plausible that thymic homeostasis is partially dependent on neurotransmitters, and

\section{REFERENCES}

Delgado, M., Garrido, E., Martínez, C., Leceta, J., and Gomariz, R. P. (1996a). Vasoactive intestinal peptide and pituitary adenylate cyclase - activating polypeptides (PACAP27 and PACAP38) protect CD4+CD8+ thymocytes from glucocorticoid-induced apoptosis. Blood 87, 5152-5161. doi: 10.1182/blood. v87.12.5152.bloodjournal87125152

Delgado, M., Martínez, C., Leceta, J., Garrido, E., and Gomariz, R. P. (1996b). Differential VIP and VIP1 receptor gene expression in rat thymocyte subsets. Peptides 17, 803-807. doi: 10.1016/0196-9781(96)00070-8

Ferone, D., Pivonello, R., Van Martin Hagen, P., Dalm, V. A. S. H., LichtenauerKaligis, E. G. R., Waaijers, M., et al. (2002). Quantitative and functional expression of somatostatin receptor subtypes in human thymocytes. Am. J. Physiol. Endocrinol. Metab. 283, 1056-1066. doi: 10.1152/ajpendo.00205. 2001

Francelin, C., and Verinaud, L. (2011). Apoptosis and the developing T cells. J. Clin. Cell. Immunol. S3:001. doi: 10.4172/2155-9899.s3-001

Geenen, V., and Savino, W. (2019). "History of the thymus: from a vestigial organ to the programming of immunological self-tolerance," in Thymus Transcriptome and Cell Biology, ed. G. A. S. Passos (Ribeirão Preto: Springer US), 1-18. doi: 10.1007/978-3-030-12040-5_1

Godinho-Silva, C., Cardoso, F., and Veiga-Fernandes, H. (2019). Neuro-immune cell units: a new paradigm in physiology. Annu. Rev. Immunol. 37, 19-46. doi: 10.1146/annurev-immunol-042718-041812

Hansenne, I., Rasier, G., Péqueux, C., Brilot, F., Renard, C., Breton, C., et al. (2005). Ontogenesis and functional aspects of oxytocin and vasopressin gene expression in the thymus network. J. Neuroimmunol. 158, 67-75. doi: 10.1016/j.jneuroim. 2004.08.007

Haskó, G., Elenkov, I. J., and Vizi, E. S. (1995). Presynaptic receptors involved in the modulation of release of noradrenaline from the sympathetic nerve terminals of the rat thymus. Immunol. Lett. 47, 133-137. doi: 10.1016/0165-2478(95) 00085-J

Kavelaars, A. (2002). Regulated expression of $\alpha-1$ adrenergic receptors in the immune system. Brain Behav. Immun. 16, 799-807. doi: 10.1016/S08891591(02)00033-8

Kawashima, K., and Fujii, T. (2004). Expression of non-neuronal acetylcholine in lymphocytes and its contribution to the regulation of immune function. Front. Biosci. 9:2063. doi: 10.2741/1390 therefore, pathological alterations in the neurotransmitters mediated circuits in the thymus may have consequences upon normal thymocyte development. Yet, the molecular mechanisms of action and control of intrathymic production and release of these neurotransmitters remain an open space for further investigation.

\section{AUTHOR CONTRIBUTIONS}

All authors equally contributed to the production of this manuscript.

\section{FUNDING}

This work was supported by Fiocruz, CNPq, CAPES, FAPERJ, and FAPESP (Brazil) and the MercoSur Fund for Structural Convergence (FOCEM). The study was developed in the frameworks of the Brazilian National Institute of Science and Technology on Neuroimmunomodulation (CNPq) and the Rio de Janeiro Research Network on Neuroinflammation (FAPERJ).

Kurz, B., von Gaudecker, B., Kranz, A., Krisch, B., and Mentlein, R. (1995). Calcitonin gene-related peptide and its receptor in the thymus. Peptides 16, 1497-1503. doi: 10.1016/0196-9781(95)02042-X

Leposavić, G., Pilipović, I., Radojević, K., Pešić, V., Perišić, M., and Kosec, D. (2008). Catecholamines as immunomodulators: a role for adrenoceptormediated mechanisms in fine tuning of T-cell development. Auton. Neurosci. Basic Clin. 144, 1-12. doi: 10.1016/j.autneu.2008.09.003

Lifantseva, N. V., Koneeva, T. O., Voronezhskaya, E. E., and Melnikova, V. I. (2017). Expression of components of the serotonergic system in the developing rat thymus. Dokl. Biochem. Biophys. 477, 401-404. doi: 10.1134/ S1607672917060151

Lifantseva, N. V., Koneeva, T. O., Voronova, S. N., Zakharova, L. A., and Melnikova, V. I. (2016). The inhibition of dopamine synthesis in fetuses changes the pattern of T-lymphocyte maturation in the thymus of adult rats. Dokl. Biochem. Biophys. 470, 342-344. doi: 10.1134/S1607672916050082

Marchetti, B., Concetta, M., Paradis, P., and Bouvier, M. (1994). Characterization, expression, and hormonal control of a thymic B2-adrenergic receptor. Am. Physiol. Soc. 267, E718-E731. doi: 10.1152/ajpendo.1994.267.5.e718

Medina, S., Del Río, M., Hernanz, A., and De la Fuente, M. (2000). The NPY effects on murine leukocyte adherence and chemotaxis change with age: adherent cell implication. Regul. Pept. 95, 35-45. doi: 10.1016/S0167-0115(00)00134-8

Mignini, F., Sabbatini, M., Capacchietti, M., Amantini, C., Bianchi, E., Artico, M., et al. (2013). T-cell subpopulations express a different pattern of dopaminergic markers in intra-and extra-thymic compartments. J. Biol. Regul. Homeost. Agents 27, 463-475.

Mignini, F., Sabbatini, M., D’Andrea, V., and Cavallotti, C. (2011). Neuropeptides of human thymus in normal and pathological conditions. Peptides 32, 920-928. doi: 10.1016/j.peptides.2011.01.022

Mignini, F., Sabbatini, M., Mattioli, L., Cosenza, M., Artico, M., and Cavallotti, C. (2014). Neuro-immune modulation of the thymus microenvironment (review). Int. J. Mol. Med. 33, 1392-1400. doi: 10.3892/ijmm.2014.1709

Mignini, F., Tomassoni, D., Traini, E., and Amenta, F. (2009). Dopamine, vesicular transporters and dopamine receptor expression and localization in rat thymus and spleen. J. Neuroimmunol. 206, 5-13. doi: 10.1016/j.jneuroim.2008.09.018

Mihovilovic, M., Denning, S., Mai, Y., Whichard, L. P., Patel, D. D., and Roses, A. D. (1997). Thymocytes and cultured thymic epithelial cells express transcripts encoding $\alpha-3, \alpha-5$ and $\beta-4$ subunits of neuronal nicotinic acetylcholine receptors: preferential transcription of the $\alpha-3$ and $\beta-4$ genes by 
immature CD4 + 8 + thymocytes. J. Neuroimmunol. 79, 176-184. doi: 10.1016/ S0165-5728(97)00120-3

Moll, U. M., Lane, B. L., Robert, F., Geenen, V., and Legros, J.-J. (1988). The neuroendocrine thymus. Histochemistry 89, 385-390. doi: 10.1007/bf00500641

Nance, D. M., and Sanders, V. M. (2007). Autonomic innervation and regulation of the immune system (1987-2007). Brain Behav. Immunol. 86, 736-745. doi: 10.1007/s11103-011-9767-z.Plastid

Pankhaniya, R., Jabrane-Ferrat, N., Gaufo, G. O., Sreedharan, S. P., Dazin, P., Kaye, J., et al. (1998). Vasoactive intestinal peptide enhancement of antigen-induced differentiation of a cultured line of mouse thymocytes. FASEB J. 12, 119-127. doi: 10.1096/fsb2fasebj.12.1.119

Panneck, A. R., Rafiq, A., Schütz, B., Soultanova, A., Deckmann, K., Chubanov, V., et al. (2014). Cholinergic epithelial cell with chemosensory traits in murine thymic medulla. Cell Tissue Res. 358, 737-748. doi: 10.1007/s00441-014-2002-x

Pešić, V., Kosec, D., Radojević, K., Pilipović, I., Perišić, M., Vidić-Danković, B., et al. (2009). Expression of $\alpha 1$-adrenoceptors on thymic cells and their role in fine tuning of thymopoiesis. J. Neuroimmunol. 214, 55-66. doi: 10.1016/j. jneuroim.2009.06.018

Pilipović, I., Vidić-Danković, B., Perišić, M., Radojević, K., Čolić, M., Todorović, V., et al. (2008). Sexual dimorphism in the catecholamine-containing thymus microenvironment: a role for gonadal hormones. J. Neuroimmunol. 195, 7-20. doi: 10.1016/j.jneuroim.2007.12.006

Radojcic, T., Baird, S., Darko, D., Smith, D., and Bulloch, K. (1991). Changes in $\beta$-adrenergic receptor distribution on immunocytes during differentiation: an analysis of $\mathrm{T}$ cells and macrpphages. J. Neurosci. Res. 30, 328-335. doi: 10.1002/jnr.490300208

Radojevíc, K., Rakin, A., Pilipovíc, I., Djikíc, J., Bufan, B., Vujnovíc, I., et al. (2014). Effects of catecholamines on thymocyte apoptosis and proliferation depend on thymocyte microenvironment. J. Neuroimmunol. 272, 16-28. doi: 10.1016/j.jneuroim.2014.04.010

Rinner, I., Globerson, A., Kawashima, K., Korsatko, W., and Schauenstein, K. (1999). A possible role for acetylcholine in the dialogue between thymocytes and thymic stroma. Neuroimmunomodulation 6, 51-55. doi: 10.1159/000026364

Robert, F., Geenen, V., Schoenen, J., Burgeon, E., De Groote, D., Defresne, M. P., et al. (1991). Colocalization of immunoreactive oxytocin, vasopressin and interleukin-1 in human thymic epithelial neuroendocrine cells. Brain Behav. Immun. 5, 102-115. doi: 10.1016/0889-1591(91)90010-8

Roggero, E., Besedovsky, H. O., and Del Rey, A. (2011). The role of the sympathetic nervous system in the thymus in health and disease. Neuroimmunomodulation 18, 339-349. doi: 10.1159/000329581

Santoni, G., Amantini, C., Lucciarini, R., Pompei, P., Perfumi, M., Nabissi, M., et al. (2002). Expression of substance $P$ and its neurokinin-1 receptor on thymocytes: functional relevance in the regulation of thymocyte apoptosis and proliferation. Neuroimmunomodulation 10, 232-246. doi: 10.1159/000068327

Savino, W., Mendes-da-Cruz, D. A., Ferreira Golbert, D. C., Riederer, I., and Cotta-de-Almeida, V. (2015). Laminin-mediated interactions in thymocyte migration and development. Front. Immunol. 6:579. doi: 10.3389/fimmu.2015. 00579

Savino, W., Mendes-Da-Cruz, D. A., Lepletier, A., and Dardenne, M. (2016). Hormonal control of T-cell development in health and disease. Nat. Rev. Endocrinol. 12, 77-89. doi: 10.1038/nrendo.2015.168

Schubert, T., and Müller, W. E. (1989). N-Formyl-methionyl-leucyl-phenylalanine induced accumulation of inositol phosphates indicates the presence of oligopeptide chemoattractant receptors on circulating human lymphocytes. FEBS Lett. 257, 174-176. doi: 10.1016/0014-5793(89)81814-9

Shenoy, A. R., Dehmel, T., Stettner, M., Kremer, D., Kieseier, B. C., Hartung, H. P., et al. (2013). Citalopram suppresses thymocyte cytokine production. J. Neuroimmunol. 262, 46-52. doi: 10.1016/j.jneuroim.2013. 06.006

Silva, B. A., Danielle, A. W., and Palmer, D. B. (2006). Evolutionary conservation of neuropeptide expression in the thymus of different species. Immunology 118, 131-140. doi: 10.1111/j.1365-2567.2006.02351.x

Singh, U., Millson, D. S., Owen, J. J. T., and Smith, P. A. (1979). Identification of $\beta$ adrenoceptors during thymocyte ontogeny in mice. Eur. J. Immunol. 9, 31-35. doi: 10.1002/eji.1830090108

Stefulj, J., Jernej, B., Cicin-Sain, L., Rinner, I., and Schauenstein, K. (2000). mRNA expression of serotonin receptors in cells of the immune tissues of the rat. Brain. Behav. Immunol. 14, 219-224. doi: 10.1006/brbi.1999.0579

Trejter, M., Warchol, J. B., De Caro, R., Brelinska, R., Nussdorfer, G. G., and Malendowicz, L. K. (2001). Studies on the involvement of endogenous neuropeptides in the control of thymocyte proliferation in the rat. Histol. Histopathol. 16, 155-158. doi: 10.14670/HH-16.155

Warthan, M. D., Freeman, J. G., Loesser, K. E., Lewis, C. W., Hong, M., Conway, C. M., et al. (2002). Phenylethanolamine N-methyl transferase expression in mouse thymus and spleen. Brain. Behav. Immun. 16, 493-499. doi: 10.1006/ brbi.2001.0637

Xin, Z., Tang, H., and Ganea, D. (1994). Vasoactive intestinal peptide inhibits interleukin (IL)-2 and IL-4 production in murine thymocytes activated via the TCR/CD3 complex. J. Neuroimmunol. 54, 59-68. doi: 10.1016/0165-5728(94) 90231-3

Conflict of Interest: The authors declare that the research was conducted in the absence of any commercial or financial relationships that could be construed as a potential conflict of interest.

Copyright (c) 2021 Francelin, Veneziani, Farias, Mendes-da-Cruz and Savino. This is an open-access article distributed under the terms of the Creative Commons Attribution License (CC BY). The use, distribution or reproduction in other forums is permitted, provided the original author(s) and the copyright owner(s) are credited and that the original publication in this journal is cited, in accordance with accepted academic practice. No use, distribution or reproduction is permitted which does not comply with these terms. 